\title{
FACTORS ASSOCIATED WITH HABITAT SEGREGATION AMONG THE FOUR SPECIES OF CERVIDS IN THE CHITWAN NATIONAL PARK, NEPAL
}

\author{
BISHNU PRASAD BHATTARAI
}

Central Department of Zoology, Institute of Science and Technology, Tribhuvan University, Kirtipur, Kathmandu, Nepal; e-mail: bpbhattarai@cdztu.edu.np, bhattaraibp@gmail.com

\begin{abstract}
Bhattarai B.P.: Factors associated with habitat segregation among the four species of cervids in the Chitwan National Park, Nepal. Ekológia (Bratislava), Vol. 38, No. 1, p. 37-48, 2019.

Study of habitat segregation among the four species of cervids was conducted in the Chitwan National park of lowland Nepal. This study aimed to investigate the possible mechanisms of habitat partitioning among the four cervids - chital, sambar deer, hog deer and northern red muntjac using discriminant analysis and canonical correlation analysis. Present study considered four major niche dimensions - habitat, human disturbance, presence of predators and seasons. The data were collected by walking along the line transects that encompasses the different habitats, varying degree of human disturbances and frequency of predator's presence. Results showed the significant effect of season on the habitat segregation among these cervids. There was higher niche overlap during summer season as compared to winter season. Habitat overlap between chital and muntjac was higher and unstable than others, which showed that they were the competitors of the same resources as enlightened by their generalist nature. Therefore, maintaining habitat heterogeneity and minimizing human disturbances will be better solutions for the coexistence of herbivores in the Chitwan National Park and can be an example for similar areas of lowland Nepal.
\end{abstract}

Key words: habitat segregation, Chitwan, deer, bengal tiger.

\section{Introduction}

Investigations of habitat utilization by large mammals, as well as their relationship with their sympatric species and the environment, are important in understanding the mechanisms that influence large mammalian community structure. In general, the sympatric species with similar niche dimensions may compete for common resources and coexist either by resource partitioning or geographical area partitioning (Schaller, 1967). Habitat selection and the niche theory explains that similar species with similar niches should be allopatric or some of their behavioural aspects that separate them spatially or temporally within the same range. The coexistence of competitive species cooccurs in the same habitat as a result of the resource partitioning (Hardin, 1960). Competition can be considered as the bioforce that cause differentiation in the use of resources by coexisting species (Pianka, 1976). Predation or different responses of species to environmental factors may also lead to resource partitioning (Wiens, 
1977). For example, similar body sized sympatric species can also compete with each other to avoid predators and such an interaction is known as 'apparent competition' (Werner et al., 1983) or competition for 'enemy-free space' (Jeffries, Lawton, 1984), and consequently, may try to adopt different escape tactics that sometimes leads to habitat or resource partitioning. In territories of large carnivores like tiger and leopard, the competition may be prevented by predation, which keeps the population of the competitors below the level at which food resources become limiting (Hutchinson, 1968; Putman, 1986). Sometimes, predation and competition come together and can affect prey community assemblage in multiple ways that often interact (Schoener, 1977; Werner et al., 1983).

The habitat segregation among the wild prey communities have been studied widely (Gordon, Illius, 1989; Voeten, Prins, 1999); however, the underlying mechanisms that initiate such partitioning remain rare. The analysis of niche differences reflects the evolutionary adjustments in a biotic community, designed to facilitate the coexistence of ecologically similar species (Dueser, Shugart, 1978; Reinert, 1984). Sometimes, similar analyses may concern the limits of ecological similarity that necessitate the resource partitioning for coexistence of multiple species in a Gaussian framework (May, 1973). It is believed that coexisting sympatric species segregate primarily by habitats and subsequently by dietary and temporal specialisations (Schoener, 1974, 1983; Toft, 1985) and also by the predators and human disturbances in the edges of habitats. The use of multivariate statistical methods like Discriminant analysis (DA) and Canonical Correlation analysis (CCA) are a popular tool for representing niche geometry and studying natural communities (Green, 1971; Dueser, Shugart, 1978; Reinert, 1984; Edge et al., 1987; Marnell, 1998; Wei et al., 2000). Here, we studied the niche dimensions of four species of cervids in the Chitwan National Park (CNP). The habitat use patterns of chital (Axis axis), sambar (Rusa unicolor), hog deer (Axis porcinus) and northern red muntjac (Muntiacus vaginalis) in different habitats were taken as the variables to measure their niche dimensions and habitat segregation by using DA and CCA.

\section{Material and methods}

\section{Study area}

The Chitwan National Park (Fig. 1) is located in the lowland Terai region of Nepal. It is one of the major habitats of tigers in the Indian subcontinent (CNP, 2018; Dhakal et al., 2014). It covers an area of $952.63 \mathrm{~km}^{2}$ and is surrounded by a buffer zone of $729.37 \mathrm{~km}^{2}$ (including $55 \%$ of agricultural land and $45 \%$ of community forest). The park consists of diverse ecosystems ranging from early stages of succession on alluvial floodplains along the Narayani, Rapti and Rew watersheds to the climax forest in the foothills and on the slopes of the Churia range. The forests here are composed predominantly of deciduous and semi-deciduous species. Sal forest covers over $70 \%$ of the park. Similarly, grasslands (both tall and short grasslands and riparian flood plains) make up to $20 \%$ of the park area. Sal (Shorea robusta) dominates in the Chitwan National Park, while the lowland areas along the rivers are covered by a mosaic of riverine forests dominated by Bombax ceiba, Trewia nudiflora and tall grasslands (Dhakal et al., 2014).

This park hosts the highest density of large mammals, including the Bengal tiger and greater one-horned rhinoceros, in South Asia. It also covers the Terai-Duar Savanna and Grassland Ecoregion, which is listed among the 200 globally important areas of biodiversity in the world, because of its rich diversity of large mammals (Wikramanayake et al., 2001). There are at least 70 species of mammals in the CNP, including tiger (Panthera tigris tigris), sloth bear (Ursus ursinus), gaur bison (Bos gaurus), greater one-horned rhinoceros (Rhinoceros unicornis) and Asian elephant (Elephas maximus) (Bhattarai, Kindlmann, 2012; CNP, 2018). This park supports a high diversity of ungulates (important tiger prey species) such as gaur bison, sambar (Rusa unicolor), chital (Axis axis), hog deer (A. porcinus), 

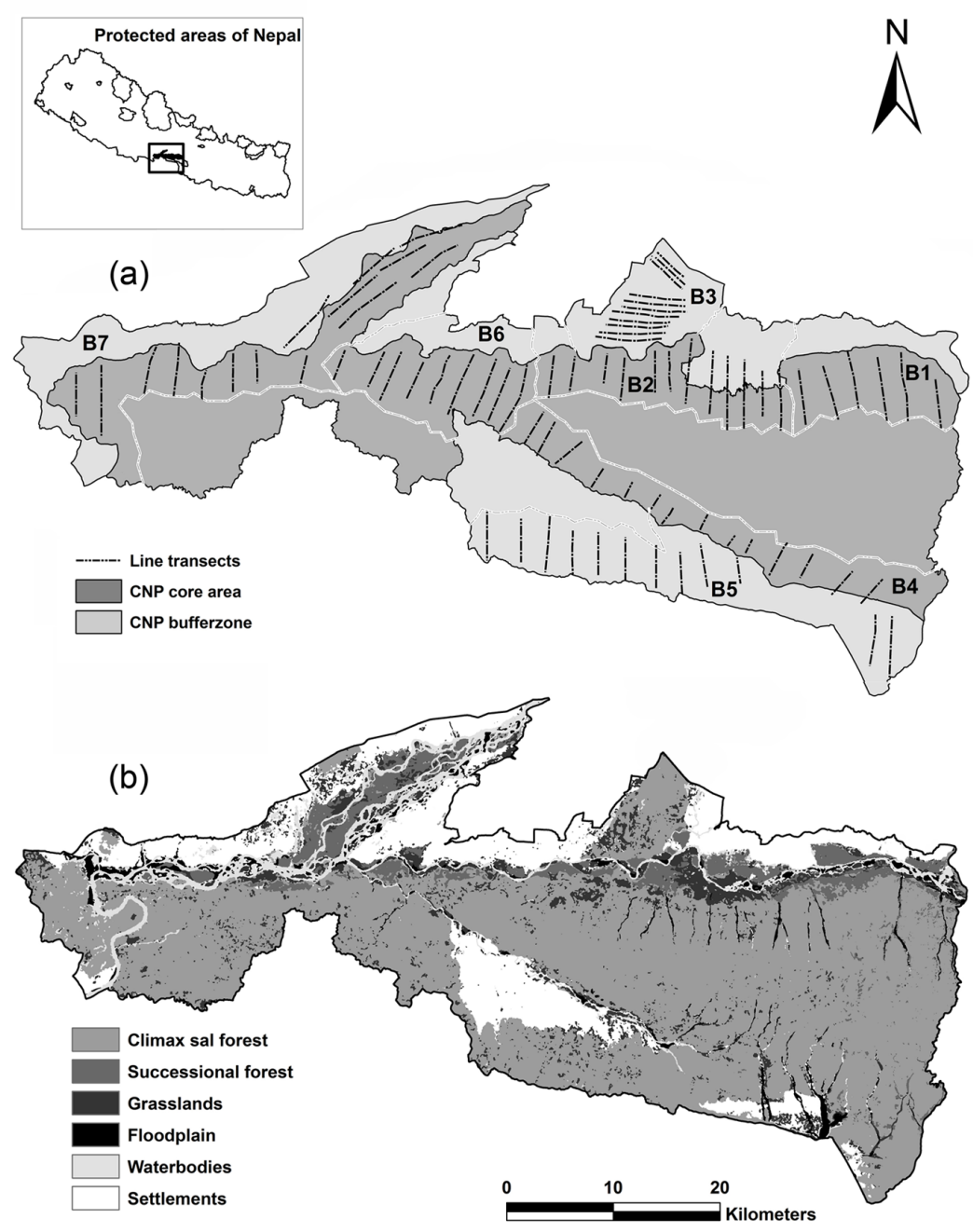

Fig. 1. Map of the study area showing different habitats and location of transects.

northern red muntjac (Muntiacus vaginalis), wild boar (Sus scrofa), common langur (Semnopithecus entellus) and rhesus monkey (Macaca mulatta) (Stoen, Wegge, 1996; Smith et al., 1999; CNP, 2018).

\section{Model species}

The cervids (deer), the major prey species of tiger in the tropical Asia, are the model species for this study. There is considerable variation in the body size, habitat selection and range of these species. Sambar deer is the large sized 
prey and distributed throughout the reserves and parks of the Terai (Mishra, 1982). Climax forest is the most preferred habitat of sambar deer and feed mainly at night and retires into heavy cover at daybreak and do not usually come out till dusk (Prater, 1998). Chital is a medium sized prey of tiger and it is found throughout the Terai, with major concentrations in the parks and reserves. Newly burned grasslands are the major feeding habitats and dense forest habitats are the resting places during the hot periods of a day for ungulates including chital (Mishra, 1982). Another medium sized deer in this area is the hog deer, which mainly inhabits the alluvial grasslands of lowlands (Dhungel, O'Gara, 1991; Mishra, 1982) and its range is decreasing. Northern red muntjac is the smallest deer in this area that mostly prefers dense forests and usually grazes in the open forest edges nearby the human settlements (Pokharel et al., 2015).

\section{Data collection}

The distribution of the four species of cervids were determined by direct observation in line transects. We walked 80 transects, twice for the year 2013 summer (April, May, June, July) and winter (November, December 2013 and January, February 2014) that covered $1154 \mathrm{~km}$. The location and length of transects were defined by the accessibility on foot. During the walks on transects, we recorded the name of cervids, their group size, presence signs of predators (tiger and leopard), habitat parameters and disturbance variables associated with them (Table 1). This sampling was carried out at every $100 \mathrm{~m}$ interval along the transect and data on the habitat gradient for each sampling point was visually recorded in $100 \mathrm{~m}$ radius plot as forest cover (Dense or Mild dense or Open); plane or gentle slope and as topography and distance to the waterholes. The distance between animal and waterholes was measured by using the topographic map (1:50,000 scale by the Survey of Nepal toposheets) of the study area. Human disturbance was enumerated by recording the signs of people and livestock presence in the same transects. The presence of signs of people were enumerated by recording the numbers of lopped trees, logged trees, grass cutting sites and the presence signs of livestock were enumerated by recording the faeces of livestock. Altogether, we had data on 18 habitat variables (Table 1) for each season. We then used these data to measure the niche dimensions for each of these cervids.

T a ble 1. Description of the habitat variables collected in Chitwan National Park during the two seasons of 2013-2014.

\begin{tabular}{|l|l|}
\hline Variables & Details of variables \\
\hline Habitat types & Sal forest \\
\hline SF & Mixed forest \\
\hline MF & Riverine forest \\
\hline RF & Tall grassland \\
\hline TGl & Short grassland \\
\hline SGl & Flood plain \\
\hline FPl & Open habitats \\
\hline Forest cover & Closed habitats \\
\hline Open & \multicolumn{2}{|l|}{} \\
\hline Closed & Plane areas \\
\hline Topography & Gentle slope areas \\
\hline Plain & \multicolumn{2}{|l|}{} \\
\hline Gslope & Presence of people: number of loped and logged trees and grass cutting sites \\
\hline Disturbance & Presence of livestock: number of faecal matter of livestock \\
\hline Peop & Distance to waterhole \\
\hline Livs & presence of predators \\
\hline Others & \\
\hline DW &
\end{tabular}




\section{Statistical analysis}

The habitat segregation among the four species of cervids was analysed by comparing their sightings data with the habitat, disturbance and predator presence across two seasons. We first carried out the multivariate analysis of variance (MANOVA) for testing the hypothesis of equality of the four group centroids (Reinert, 1984; Schneier, 1993) using Pillai's trace as the test statistic (Venables, Ripley, 1994). Again, we also performed a pair-wise multiple comparison of different groups of cervids as chital-muntjac, chital-hog deer, chital-sambar deer, muntjac-hog deer, muntjac-sambar deer and sambar deer-hog deer by using the Hotelling's T-square test. Suggested by the results of MANOVA, the identified distinct groups of cervids were later examined and tested by the stepwise Discriminant Function Analysis (DFA) to know how these species were separated with each other in terms of difference in habitat use (Green, 1971; Dueser, Shugart, 1978; Reinert, 1984; Edge et al., 1987; Marnell, 1998; Wei et al., 2000). We adopted the stepwise method in DFA to support and maximise the Mahalanobis distance between the group-centroids (Edge et al., 1987). The degree of habitat overlap was obtained from the scores of Discriminant Function of a secondary DFA model for all four species (May, MacArthur, 1972; May, 1973, 1975). Furthermore, the box's modification of Bartlett's test was used to evaluate the homogeneity of covariance matrices.

Analyses were carried out with data from two seasons using S-Plus (Venables, Ripley, 1994) and CANOCO (CANOCO v. 4.5; ter Braak, Šmilauer, 2002). We used CCA to visualize how these four species of cervids associated with the habitats, disturbances, predator presence across two seasons. CCA is a form of canonical ordination, which uses multivariate ordination and multiple regression statistical techniques to relate the species abundance data with the multiple environmental factors (ter Braak, 1986; ter Braak, Prentice, 1988)). In addition to the graphical representation of data spread in a biplot (MacFaden, Capen, 2001), a CCA reveals the relative contribution of each explanatory variable to the variance in the response variable. We selected CCA because it is robust to analyse with multiple correlated variables (Palmer, 1993). We used automatic forward selection procedure during the CCA in CANOCO, to identify the variables that best explained the variance in the data. Monte Carlo permutation test (using 499 unrestricted permutations) was performed to identify the environmental variables that significantly explained the variation in the distribution of animals.

\section{Results}

The study recorded 352 groups of chital, 124 sambar deer, 44 hog deer and 83 groups of muntjac. Based on these sightings, the results showed that these four species of cervids utilised significantly different habitat features (MANOVA- Winter: Pillai's trace $=0.08, F(15$, $837)=21.93, P<0.0001$; Summer: Pillai's trace $=0.12 F(15,837)=21.93, P<0.0001)$. The results obtained from Hotelling's T-square test revealed that there were four distinct groups of cervids and used different habitat features in each season (Table 2). To evaluate the homogeneity of covariance matrices, we used Box's modification of Bartlett's test and found that the

T a b l e 2. Pair-wise comparison by Hotelling's T-square test for equality of group-centroids of four species in Chitwan National Park, in terms of habitat-use; across two seasons.

\begin{tabular}{|l|c|c|c|c|}
\hline Species pair & \multicolumn{2}{|c|}{ F- value } & \multicolumn{2}{c|}{ Hotelling's T-square probability } \\
\hline & $\begin{array}{c}\text { Winter } \\
(\mathrm{df}=15,126)\end{array}$ & $\begin{array}{c}\text { Summer } \\
(\mathrm{df}=15,158)\end{array}$ & Winter & Summer \\
\hline Chital-hog deer & 15.18 & 0.71 & $<0.0001$ & 0.492 \\
\hline Chital-sambar deer & 13.51 & 2.2 & $<0.0001$ & 0.117 \\
\hline Chital-muntjac & 17.07 & 7.78 & $<0.0001$ & 0.001 \\
\hline Muntjac-hog deer & 8.33 & 8.25 & $<0.0001$ & $<0.0001$ \\
\hline Muntjac-sambar deer & 7.53 & 9.55 & 0.001 & $<0.0001$ \\
\hline Sambar-deer-hog deer & 4.35 & 2.57 & 0.014 & 0.079 \\
\hline
\end{tabular}


covariance matrices were not equal for both seasons (Winter: Box's $M=123.8, F(18,73928)=$ 6.70, $P<0.0001$; Summer: Box's $M=52.6, F(18,49558)=3.89, P<0.01)$, suggesting that four species of cervids exhibit different patterns of variation with respect to original variables.

Four different discriminant functions were constructed as followed by the results of MANOVA. The cervids showed the significant Discriminant Function for each season independently (Table 3). These results implied that chital segregated from other cervid species by riverine forest, short grassland, flood plain, distance to waterhole and presence of predators during winter season. While during summer season, chital segregated from other species by mixed forest, short grasslands, predator presence and human disturbances (Table 3). Likewise, muntjac segregated from other species by mixed forest and riverine forest during winter, while it segregated from other species by mixed forest and predator presence during summer season. Sambar deer was segregated from other cervids by mixed forest and predator presence during winter, while mixed forest, predator presence and disturbance during summer season. Hog deer was segregated from other species by tall grassland, floodplain and predator presence during winter while tall grassland, open canopy habitats and predator presence during summer season (Table 3). Besides, niche overlap and differences in resource

T a b l e 3. Summary of significant Discriminant Functions developed by stepwise.

\begin{tabular}{|l|c|c|c|c|c|c|c|c|}
\hline \multirow{2}{*}{ Results } & \multicolumn{2}{|c}{ Chital } & \multicolumn{2}{c}{ Muntjac } & \multicolumn{2}{c|}{ Sambar deer } & \multicolumn{2}{c|}{ Hog deer } \\
\cline { 2 - 9 } & Winter & Summer & Winter & Summer & Winter & Summer & Winter & Summer \\
\hline Eigenvalue & 0.26 & 0.14 & 0.03 & 0.032 & 0.08 & 0.09 & 0.08 & 0.07 \\
\hline CC & 0.454 & 0.345 & 0.15 & 0.18 & 0.257 & 0.29 & 0.27 & 0.26 \\
\hline Chi-square & 96.37 & 52.82 & 9.06 & 12.73 & 28.62 & 34.7 & 30.05 & 28.3 \\
\hline df & 5 & 6 & 2 & 2 & 2 & 3 & 3 & 3 \\
\hline p- value & $<.0001$ & $<0.0001$ & 0.011 & 0.002 & $<0.0001$ & $<0.0001$ & $<0.0001$ & $<0.0001$ \\
\hline SF & 0.14 & -0.116 & -0.554 & -0.19 & -0.114 & -0.072 & -0.339 & -0.209 \\
\hline MF & 0.133 & $\mathbf{0 . 4 1 7}$ & $\mathbf{0 . 7 0 1}$ & $\mathbf{0 . 7 8 1}$ & $\mathbf{0 . 5 7 8}$ & $\mathbf{0 . 4 5 8}$ & -0.125 & 0.046 \\
\hline RF & $\mathbf{- 0 . 2 2 8}$ & -0.048 & $\mathbf{0 . 5 4 3}$ & -0.149 & -0.138 & -0.075 & -0.307 & -0.134 \\
\hline TGl & 0.024 & -0.147 & -0.362 & -0.101 & -0.08 & -0.125 & $\mathbf{0 . 5 1 2}$ & $\mathbf{0 . 3 9 4}$ \\
\hline SGl & $\mathbf{0 . 2 6 5}$ & 0.373 & -0.101 & -0.007 & -0.042 & 0.002 & -0.066 & -0.023 \\
\hline FPl & $\mathbf{- 0 . 2 8 9}$ & -0.157 & -0.153 & -0.041 & -0.138 & -0.027 & $\mathbf{0 . 7}$ & 0.089 \\
\hline Open & 0.058 & -0.104 & -0.104 & -0.129 & 0.016 & -0.114 & 0.082 & $-\mathbf{0 . 3 2}$ \\
\hline Closed & -0.057 & 0.104 & 0.101 & 0.129 & -0.014 & 0.114 & -0.083 & 0.32 \\
\hline Plain & -0.065 & 0.088 & 0.169 & 0.142 & 0.024 & 0.089 & 0.091 & 0.147 \\
\hline Gslope & 0.065 & -0.088 & -0.169 & -0.142 & -0.024 & -0.089 & -0.091 & -0.147 \\
\hline DW & $\mathbf{0 . 3 0 4}$ & -0.07 & 0.133 & -0.034 & 0.207 & -0.026 & -0.06 & -0.007 \\
\hline PP & $\mathbf{0 . 8 5 6}$ & $\mathbf{0 . 5 8 2}$ & 0.064 & $\mathbf{0 . 6 7 7}$ & $\mathbf{0 . 8 5 9}$ & $\mathbf{0 . 8 2 2}$ & $\mathbf{0 . 2 5 2}$ & $\mathbf{0 . 7 8 4}$ \\
\hline Livs & -0.023 & $-\mathbf{0 . 3 7 6}$ & -0.046 & -0.075 & 0.014 & 0.0001 & 0.092 & -0.058 \\
\hline Peop & -0.063 & $\mathbf{- 0 . 4 0 7}$ & 0.003 & -0.044 & -0.036 & -0.025 & 0.111 & 0.044 \\
\hline
\end{tabular}

Notes: DFA to differentiate between the four species of cervids (chital, sambar, hog deer and muntjac) of Chitwan National Park, for two seasons. Significance tests were carried out for those variables (highlighted) by the absolute size of correlation within function. CC, Canonical correlation; df, degrees of freedom and details of other variables are explained in Table 1. 
a)

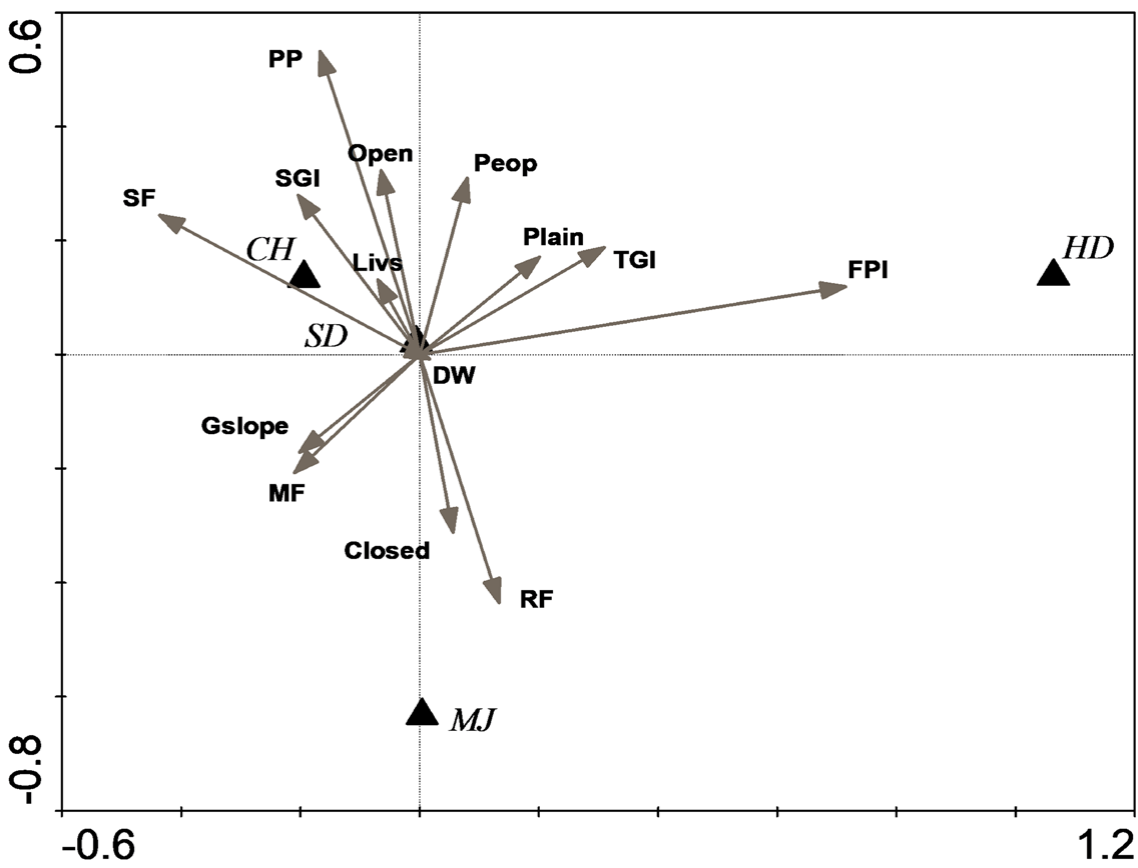

b)

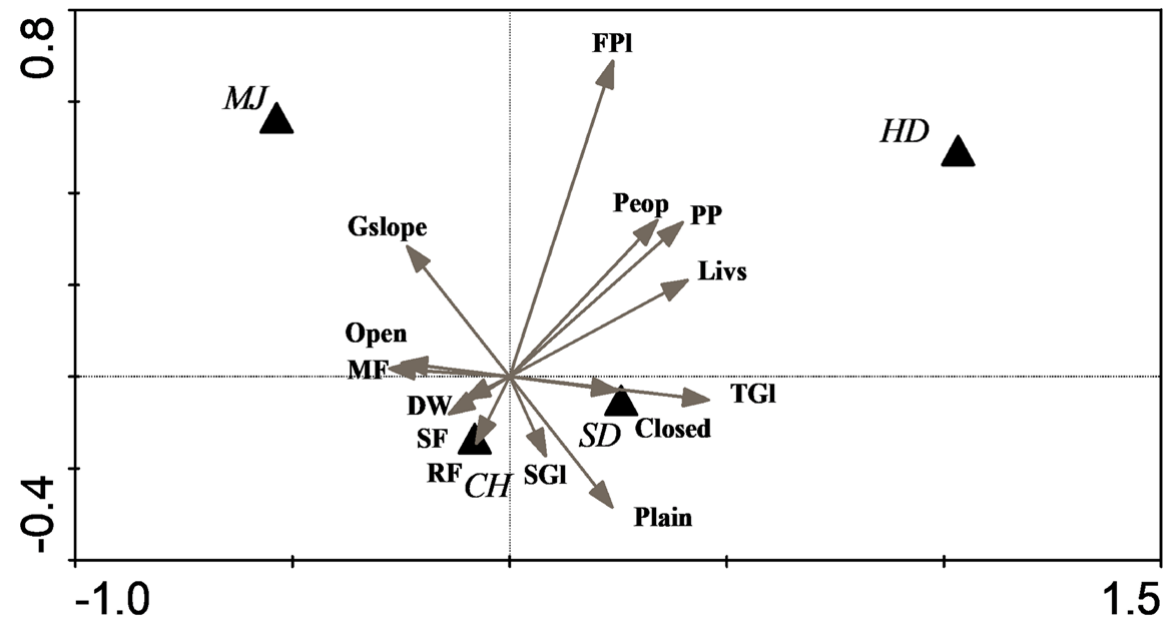

Fig. 2. CCA ordination diagram showing habitat separation among four species of cervids in the Chitwan National Park for two seasons. Monte-Carlo permutation test of significance of all canonical axes (a) winter season: Trace = $0.20, F=2.24, P=0.002$ (with 499 permutations). First two axes are displayed. The first axis explains $58.7 \%$ and the second axis explains $32.4 \%$ of the total variability. (b) summer season: Trace $=0.21, F=2.01, P=0.002$ (with 499 permutations). First two axes are displayed. The first axis explains $52.2 \%$ and the second axis explains $30.3 \%$ of the total variability. 
availability also influence the reproductive rates of some deer species (Green et al., 2017). The results of discriminant function analysis were also supported by the CCA. It gives the clear picture of the relationship among the species in terms of habitat use. Figure 2 ( $a$ and $b$ ) showed that the species exhibits significant habitat separation in both the seasons. In these CCA diagrams, sambar deer and chital are close with each other compared to muntjac and hog deer, which are separated from each other as well as with the chital and sambar deer.

\section{Discussion}

\section{Habitat separation}

The habitat segregation helps to reduce both interference and competition, and facilitates coexistence of ecologically similar (sympatric) species (Pianka, 1976), like four species of cervids in the CNP. In general, the sympatric ungulates tend to use different habitats (Gordon, Illius, 1989). However, these species are ecologically similar to each other, a closer examination in this study revealed that there were in fact four groups or 'guilds' (Table 2). If the preference and the avoidance of a habitat by one species differs with the others, then habitat segregation may occur. Chital and sambar were close to each other in terms of habitat use as compared to muntjac and hog deer (Table 3). Chital segregated from other species by riverine forest, short grassland, floodplain, distance to waterhole and presence of predator during winter season; while during summer, it segregated from others again from short grasslands and predators' presence, mixed forest and human disturbances. It was mostly recorded in the ecotones such as forest and grassland border (Schaller, 1967; Eisenberg, 1981; Bagchi, 2001). The sambar deer is the largest deer in terms of body mass and it has a long distribution range as compared to the other species, and was segregated from others by mixed forest and predator presence during summer, while mixed forest, predator presence and disturbance during summer season. Sambar mostly occurred in the forested areas, which is also supported by its oriental origin and has evolved in forested environments (Schaller, 1967; Corbet, Hill, 1992). The smallest deer in this area is muntjac, which is adapted to live near human settlements in forest edges, and is segregated from other larger cervids by mixed forest and riverine forest during winter; while it is segregated from other species by mixed forest and predator presence during summer season (Pokharel et al., 2015). Among the four cervids, hog deer has quite a different preference in terms of habitats. It was segregated from other species by tall grassland, floodplain and predator presence during summer, while tall grassland, open habitats and predator presence during summer season. Some earlier studies on diet and resource partitioning at various scales suggest that resource partitioning occurs mainly at the diet level (Endo et al., 2017) and less at spatial level, but the differences are possible in small-scale habitat use (Tobler et al., 2009). Such patterns of habitat segregation among these cervids suggested a useful insight into the evolutionary history of these species (Schaller, 1967; Corbet, Hill, 1992; Eisenberg, 1981).

\section{Habitat overlap}

The multivariate approach of habitat segregation and overlap (May, MacArthur, 1972) among the four ecologically similar cervids in the Chitwan National Park of Nepal was studied by 
using the DA and CCA, instead of using univariate measure of the habitat overlap. This study implied that the habitat selection and overlap among the ungulates not only depend on the habitat types but also depend on the other factors associated with the habitats such as open or closed canopy, distance to waterhole, topographic features and human disturbances (Wang et al., 2018). This study also considered the predator presence as the principal factor that has a significant impact on the separation of the habitats because these four species of cervids are the principal prey species of tiger and leopard in this area. The results obtained from the measurement of habitat overlap among these four cervids by taking the ratio of distance between group centroids $(d)$ to the variance along the resource axis $(w)$. For these data, $d$ was the difference between mean discriminant scores and $w$ was standard deviation of the scores for each species that are derived from the second DFA model created with all four groups (May, MacArthur, 1972). The study found an asymmetrical habitat-overlap matrix of species that may be due to different habitat-breadths. The habitat overlap decreases with an increase in the magnitude of the ratio $(d / w)$ and it has been theoretically determined to approximate or exceed 1.0 for stable coexistence in a community (May, MacArthur, 1972; May, 1973). This ratio also explains the competition coefficient, as the magnitude of $\mathrm{d} / \mathrm{w}$ is inversely related to the competition coefficient and May (1973) used this model for multi-species interaction in ecological communities by non-linear differential equations. It means that the habitat overlap matrix (Table 4) is analogous to the community-matrix of Levins (1968) and May (1973, 1975). Hence, these explanations suggested that lower the values of $d / w$, the higher is the competitive coefficient and consequent effects on population of interacting species. However, if $d>w$, then there is minimal competitive interaction (May, 1973) and subsequent population stability. If so, the instability was found in the overlap between sambar and chital in both seasons (ratio: 0.19 to 0.39 ) and between sambar and muntjac in winter and summer seasons (ratio: $0.38,0.49$ ). Likewise, the instability was also found in between muntjac and chital in winter season (ratio: 0.49) and between hog deer and chital (ratio: 0.15) and hog deer and muntjac (ratio: 0.30) during winter season (Table 4). This apparent instability between sambar deer with chital and muntjac can potentially cause fluctuations in the latter's population because chital occurs in much higher densities than other deer in this park. There is increasing evidence that semiarid ungulate assemblies are disequilibrial (Ellis, Swift, 1988; Illius,

T a b le 4. Asymmetrical habitat-overlap matrix of the four species of cervids in the Chitwan National Park for two seasons.

\begin{tabular}{|l|l|c|c|c|c|}
\hline \multirow{2}{*}{ Seasons } & \multirow{2}{*}{ species } & \multicolumn{4}{|c|}{ Niche overlap } \\
\cline { 3 - 6 } & & Chital & Muntjac & Sambar & Hog deer \\
\hline \multirow{4}{*}{ Winter } & Chital & - & 2.06 & 5.38 & 6.83 \\
\cline { 2 - 6 } & Muntjac & $0.49^{\star}$ & - & 2.62 & 3.32 \\
\cline { 2 - 6 } & Sambar & $0.19^{\star}$ & $0.38^{\star}$ & - & 1.27 \\
\cline { 2 - 6 } & Hog deer & $0.15^{\star}$ & $0.30^{\star}$ & 0.79 & - \\
\hline \multirow{5}{*}{ Summer } & Chital & - & 1.26 & 2.58 & 1.86 \\
\cline { 2 - 6 } & Muntjac & 0.79 & - & 2.05 & 1.47 \\
\cline { 2 - 6 } & Sambar & $0.39^{\star}$ & $0.49^{\star}$ & - & 0.72 \\
\cline { 2 - 6 } & Hog deer & 0.54 & 0.68 & 1.39 & - \\
\hline
\end{tabular}

O'Connor, 1999; Bagchi, 2001; Wang et al., 2018) and these data seem to suggest that the extent of ecological similarity might be a determinant of theoretically predictable population fluctuations. But the relationship between chital and sambar is likely due to forage limitations during winter and might not be a permanent feature in the community 
(as suggested by the high ratio in summer than winter season, Table 4). Such a situation can arise due to seasonal fluctuations in forage quality and quantity in such semiarid environments of tropical and subtropical forests. However, heterogeneity in the habitats can be the better options under such circumstances as there is considerable variability in forage availability in different habitats with respect to different seasons (Bhattarai, Kindlmann, 2012).

\section{Conclusion}

In Chitwan National Park, the four species of cervids showed different niche primarily according to forest types. The overlap between chital and sambar deer occurs due to scarcity of forage in dry season. The study found unstable habitat overlap between chital and muntjac that was due to difference in their body size and significantly unequal populations. Niche overlap and competition among the four species of cervids were found to be lower in the areas with high habitat heterogeneity. Such areas can provide multiple resources and facilitate a stable state of coexistence of sympatric species. Present results help to improve the knowledge about the niche ecology of four major cervids of lowland Nepal that directly link with the conservation of large predators like tiger and leopard. These findings suggest a possible relation between niche-overlap and population fluctuations among cervids. Further studies on population dynamics of these species would help to develop a detailed understanding about the functioning of such tropical and subtropical ecosystems of lowland Nepal. Maintaining high diversity in the habitats and minimizing human disturbances will help to build the conservation strategies for the long term coexistence of these four species of cervids in the Chitwan National Park.

\section{Acknowledgements}

I am grateful to the Department of National Parks and Wildlife Reserves for the permission to work in the CNP. I thank all the members and the volunteers from the Himalayan Environment \& Public Health Network (HEPHN) who helped during the field work: Tika Pariyar, Madan Dhungana, Shankar Shrestha and Mukunda Aryal.

\section{References}

Bagchi, S. (2001). Resource selection and resource partitioning among wild ungulates in the tropical semiarid forest of Ranthambhore National Park, Rajasthan. Masters dissertation, Saurashtra University, Rajkot, India.

Bhattarai, B.P. \& Kindlmann P. (2012). Habitat heterogeneity as the key determinant of the abundance and habitat preference of prey species of tiger in the Chitwan National Park, Nepal. Acta Theriol., 57, 89-97. DOI: 10.1007/ s13364-011-0047-8.

CNP (2018, June). Biodiversity of the Chitwan National Park. www.chitwannationalpark.gov.np/index.php/biodiversity

Corbet, G.B. \& Hill J.E. (1992). The Mammals of the Indomalayan Region: A Systematic Review. Oxford: Oxford University Press.

Dhakal, M., Karki, M., Jnawali, S.R., Subedi, N., Pradhan, N.M.B., Malla, S., Lamichhane, B.R., Pokheral, C.P., Thapa, G.J., Oglethorpe, J., Subba, S.A., Bajracharya, P.R. \& Yadav H. (2014). Status of tigers and prey in Nepal. Kathmandu: Department of National Parks and Wildlife Conservation Nepal.

Dhungel, S.K. \& O'Gara B.W. (1991). Ecology of the hog deer in Royal Chitwan National Park, Nepal. Wildlife Monograph No. 119. Bethesda: Wildlife Society.

Dueser, R.D. \& Shugart Jr. H.H. (1978). Microhabitats in a forest-floor small mammal fauna. Ecology, 59, 89-98. DOI: $10.2307 / 1936634$. 
Edge, D.W., Marcum, C.L. \& Olson-Edge S.L. (1987). Summer habitat selection by elk in western Montana: A multivariate approach. J. Wildl. Manag., 51, 844-851.

Eisenberg, J.F. (1981). The mammalian radiations: an analysis of trends in evolution, adaptation and behaviour. London: The Athlone Press.

Ellis, J.E. \& Swift D.M. (1988). Stability of African pastoral ecosystems: alternate paradigms and implications for development. J. Range Manag., 41, 450-459. DOI: 10.2307/3899515.

Endo, Y., Takada, H. \& Takatsuki S. (2017). Comparison of the food habits of the sika deer (Cervus nippon), the Japanese serow (Capricornis crispus), and the wild boar (Sus scrofa), sympatric herbivorous mammals from Mt. Asama, Central Japan. Mamm. Study, 42, 131-140. DOI: 10.3106/041.042.0303.

Gordon, I.J. \& Illius A.W. (1989). Resource partitioning by ungulates in the Isle of Rhum. Oecologia, 79, 383-389. DOI: $10.1007 / \mathrm{BF} 00384318$.

Green, M.L., Kelly, A.C., Satterthwaite-Phillips, D., Manjerovic, M.B., Shelton, P., Novakofski, J. \& Mateus-Pinilla N. (2017). Reproductive characteristics of female white-tailed deer (Odocoileus virginianus) in the Midwestern USA. Theriogenology, 94, 71-78. DOI: 10.1016/j.theriogenology.2017.02.010.

Green, R.H. (1971). A multivariate statistical approach to the Hutchinsonian niche: Bivalve molluscs of central Canada. Ecology, 52, 543-556. DOI: 10.2307/1934142.

Hardin, G. (1960). The competitive exclusion principle. Science, 131, 1292-1297. DOI: 10.1126/science.131.3409.1292.

Hutchinson, G.E. (1968). When are species necessary? In R.C. Lewontin (Ed.), Population biology and evolution (pp. 177-186). Syracuse, New York: Syracuse University Press.

Illius, A.W. \& O'Connor T.G. (1999). On the relevance of nonequilibrium concepts to semiarid grazing systems. Ecol. Appl., 9, 798-813. DOI: 10.1890/1051-0761(1999)009[0798:OTRONC]2.0.CO;2.

Jeffries, M.J. \& Lawton J.H. (1984). Enemy-free space and the structure of ecological communities. Biology Journal of Linnean Society, 23, 269-286. DOI: 10.1111/j.1095-8312.1984.tb00145.x.

Levins, R. (1968). Evolution in changing environments: some theoretical explorations. Princeton, NJ: Princeton University Press.

MacFaden, S.W. \& Capen D.E. (2001). Avian habitat relationships at multiple scales in a New England forest. For. Sci., 48, 243-253. DOI: 10.1093/forestscience/48.2.243.

Marnell, F. (1998). Discriminant analysis of the terrestrial and aquatic habitat determinants of the smooth newt (Triturus vulgaris) and the common frog (Rana temporaria) in Ireland. J. Zool. (Lond.), 244, 1-6. DOI: 10.1111/ j.1469-7998.1998.tb00001.x.

May, R.M. \& MacArthur R.H. (1972). Niche overlap as a function of environmental variability. Proc. Natl. Acad. Sci. USA, 69, 1109- 1113. DOI: 10.1073/pnas.69.5.1109.

May, R.M. (1973). Stability and complexity in model ecosystems. New Jersey: Princeton University Press.

May, R.M. (1975). Some notes on estimating the competition matrix a. Ecology, 56, 737-741. DOI: 10.2307/1935511.

Mishra, H.R. (1982). The ecology and behaviour of chital (Axis axis) in the Royal Chitwan National Park, Nepal. Unpublished doctoral dissertation, University of Edinburgh, UK.

Palmer, M.W. (1993). Putting things in even better order: The advantages of canonical correspondence analysis. Ecology, 74, 2215-2230. DOI: 10.2307/1939575.

Pianka, E.R. (1976). Competition and niche theory. In R.M. May (Ed.), Theoretical ecology. Oxford: Blackwell Scientific Publications.

Pokharel, K.P., Ludwig, T. \& Storch I. (2015). Spatial niche partitioning in sub-tropical solitary ungulates: fourhorned antelope and barking deer in Nepal. PLoS ONE, 10(2), e0117917. DOI: 10.1371/journal.pone.0117917.

Prater, S.H. (1998). The book of Indian animals. Bombay: Bombay Natural History Society and Oxford University Press, Mumbai, India.

Putman, R.J. (1986). Competition and coexistence in a multispecies grazing system. Acta Theriol., 31, 271-291.

Reinert, H.K. (1984). Habitat separation between sympatric snake populations. Ecology, 65, 478-486. DOI: $10.2307 / 1941410$.

Schaller, G.B. (1967). The deer and the tiger: a study of wildlife in India. Chicago: University of Chicago Press.

Schneier, S.M. (1993). Multiple response variables and multispecies interactions. In S.M. Schneier \& J. Gurevitch (Eds.), Design and analysis of ecological experiments (pp. 94-112). London: Chapman and Hall.

Schoener, T.W. (1974). Resource partitioning in ecological communities. Science, 185, 27-39. DOI: 10.1126/science.185.4145.27.

Schoener, T.W. (1977). Competition and niche. In C. Gans \& D. Tinkle (Eds.), Biology of the Reptilia, Vol. 7 (pp. 35-136). New York: Academic Press. 
Schoener, T.W. (1983). Field experiments on interspecific competition. Am. Nat., 122, 240-285. DOI: 10.1086/284133.

Smith, J.L.D., McDougal, C., Ahearn, S.C., Joshi, A. \& Conforti, K. (1999). Metapopulation structure of tigers in Nepal. In J. Seidensticker, S. Christie \& P. Jackson (Eds.), Riding the tiger: tiger conservation in human-dominated landscapes (pp. 176-189). Cambridge: Cambridge University Press.

Stoen, O.G. \& Wegge P. (1996). Prey selection and prey removal by tiger (Panthera tigris) during the dry season in lowland Nepal. Mammalia, 60, 363-373.

ter Braak, C.J.F. (1986). Canonical correspondence analysis: A new eigenvector technique for multivariate direct analysis. Ecology, 67, 1167-1179. DOI: 10.2307/1938672.

ter Braak, C.J.F. \& Prentice I.C. (1988). A theory of gradient analysis. Adv. Ecol. Res., 18, 271-317. DOI: 10.1016/ S0065-2504(08)60183-X.

ter Braak, C.J.F. \& Šmilauer P. (2002). CANOCO reference manual and CanoDraw for Windows User's Guide: Software for Canonical Community Ordination (version 4.5). Wageningen/České Budějovice: Biometris.

Tobler, M.W., Carrillo-Percastegui, S.E. \& Powell G. (2009). Habitat use, activity patterns and use of mineral licks by five species of ungulate in south-eastern Peru. J. Trop. Ecol., 25, 261-270. DOI: 10.1017/S0266467409005896.

Toft, C.A. (1985). Resource partitioning in amphibians and reptiles. Copeia, 1985, 1-21. DOI: 10.2307/1444785.

Venables, W.N. \& Ripley B.D. (1994). Modern applied statistics with S-Plus. New York: Springer-Verlag.

Voeten, M.M. \& Prins H.H.T. (1999). Resource partitioning between sympatric wild and domestic herbivores in the Tarangire region of Tanzania. Oecologia, 120, 287-294. DOI: 10.1007/s004420050860.

Wang, J., Wang, P., Aryal, A., Meng, X., \& Weladji, R.B. (2018). Summer habitat selection of reindeer (Rangifer tarandus) governs on the unprotected forest and human interface in china. Ekológia (Bratislava), 37(2), 112-121. DOI: $10.2478 /$ eko-2018-0011.

Wei, F., Feng, Z., Wang, Z. \& Hu J. (2000). Habitat use and separation between the giant panda and the red panda. J. Mammal., 81, 448-455. DOI: 10.1644/1545-1542(2000)081<0448:HUASBT>2.0.CO;2.

Werner, E.E., Gilliam, J.F., Hall, D.F. \& Mittelbach G.G. (1983). An experimental test of the effects of predation risk on habitat use in fish. Ecology, 64, 1540-1548. DOI: 10.2307/1937508.

Wiens, J.A. (1977). On competition and variable environments: populations may experience "ecological crunches" in variable climates, nullifying the assumptions of competition theory and limiting the usefulness of short-term studies of population patterns. Am. Sci., 65, 592-597. https://www.jstor.org/stable/27848086

Wikramanayake, E., Dinerstein, E., Loucks, C., Olson, D., Morrison, J., Lamoreux, J., McKnight, M. \& Hedao P. (2001). Terrestrial ecoregions of the Indo-Pacific: A conservation assessment. Washington: Island Press. 